thân bằng kit Tropocell điều trị viêm lồi cầu ngoài xương cánh tay có tác dụng giảm đau, cải thiện chức năng vận động tại vùng lồi cầu ngoài xương cánh tay tốt hơn nhóm tiêm Depo Medrol trên tất cả các thông số đánh giá thang điểm VAS, Q-DASH, PRTEE. Liệu pháp an toàn với tỷ lệ đau tăng sau tiêm là $12,5 \%$ và không gặp trưởng hợp nào nhiễm khuẩn phần mềm.

\section{TÀI LIÊU THAM KHẢO}

1. Nguyễn Ngọc Lan. Bệnh Học Cơ Xương Khớp Nội Khoa. Nhà xuất bản y học; 2009.

2. Lai WC, Erickson BJ, Mlynarek RA, Wang D. Chronic lateral epicondylitis: challenges and solutions. OAJSM. 2018; Volume 9:243-251. doi:10.2147/OAJSM.S160974

3. Peerbooms JC, Sluimer J, Bruijn DJ, Gosens T. Positive Effect of an Autologous Platelet Concentrate in Lateral Epicondylitis in a DoubleBlind Randomized Controlled Trial: Platelet-Rich Plasma Versus Corticosteroid Injection with a 1Year Follow-up. Am J Sports Med. 2010;38(2):255-
262. doi: $10.1177 / 0363546509355445$

4. Yadav R. Comparison of Local Injection of Platelet Rich Plasma and Corticosteroids in the Treatment of Lateral Epicondylitis of Humerus. JCDR. Published online 2015. doi:10.7860/ JCDR/2015/ 14087.6213

5. Pietrzak WS, Eppley BL. Platelet Rich Plasma: Biology and New Technology: Journal of Craniofacial Surgery. 2005;16(6):1043-1054. doi:10.1097/01.scs.0000186454.07097.bf

6. Factor D, Dale B. Current concepts of rotator cuff tendinopathy.Int J Sports Phys Ther. 2014;9 (2):274-288.

7. Nguyễn Trân Trung Đ.H.H. Đánh Giá Kết Quả Của Liệu Pháp Huyết Tương Giàu Tiểu Cầu Tự Thân Trong Điêu Trị Viêm Lôi Cầu Ngoài Xương Cánh Tay,. Luân văn thac sĩ Y họ, Đại họ Y Hà Nội; 2015.

8. Filardo G, Kon E, Pereira Ruiz MT, et al. Platelet-rich plasma intra-articular injections for cartilage degeneration and osteoarthritis: singleversus double-spinning approach. Knee Surg Sports Traumatol Arthrosc. 2012;20(10):20822091. doi:10.1007/s00167-011-1837-x

\title{
XÁC ĐỊNH TỶ LÊ MẤT NGỦ CẤP TÍNH VÀ MộT Số YẾU Tố LIÊN QUAN TRÊN BỆNH NHÂN CHẤN THƯƠ'NG SỌ NÃO
}

\section{TÓM TẮT}

Mục tiêu: Xác định tỷ lệ, đặc điểm lâm sàng mất ngủ cấp tính, mối liên quan của một số yếu tố với mất ngủ cẩp tính khởi phát trên bệnh nhân chấn thương sọ não. Đối tượng và phương pháp nghiên cứu: 225 bệnh nhân bị chấn thương sọ não điều trị tại khoa Phẩu thuật thần kinh bệnh viện Quân y 175 bằng phương pháp tiến cứu, mô tả cắt ngang. Kết quả: Có $30.67 \%$ số bệnh nhân thỏa mãn tiêu chuẩn chẩn đoán mất ngủ cấp tính theo DSM-5. Bệnh nhân mất ngủ cấp tính có thời gian vào giấc ngủ trung bình là $65.65 \pm 50.34$ phút, tổng thời gian ngủ trung bình mỗi đêm là $4.71 \pm 1.08$ giờ. Đa số bệnh nhân than phiền mất ngủ xuất hiện hầu hết các ngày trong tuần và thường gặp là mất ngủ đầu giấc. Số lần thức giấc

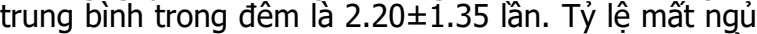
cấp tính không phụ thuộc vào giới tính, nhóm tuổi, mức độ chấn thương so não. Tỷ lệ này cao hơn trong số các bệnh nhân có triệu chứng đau đâu, có hình ảnh dập và hoặc/xuất huyết não, di lệch đường giữa trên phim chụp cắt lớp vi tính so não.

Tư khóa: mất ngủ, chẩn thương sọ não

${ }^{1}$ Bênh viện Quân y 175

${ }^{2}$ Trường Đại Hoc Y Dượ Tp HCM

${ }^{3}$ Bệnh viện Quần y 103

Chịu trách nhiệm chính: Đặng Trần Khang

Email: bskhangv175@gmail.com

Ngày nhận bài: 9.4.2021

Ngày phản biên khoa hoc: 25.5.2021

Ngày duyệt bài: 10.6 .2021

\section{SUMMARY}

DETERMINING THE RATE OF ACUTE INSOMNIA AND SOME RELATED FACTORS IN PATIENTS WITH TRAUMATIC BRAIN INJURY

Objectives: Determine the rate, clinical features of acute insomnia, the relationship of some factors to acute onset insomnia in patients with traumatic brain injury. Subjects and research methods: Study of 225 patients with traumatic brain injury treated at the Department of Neurosurgery at Military Hospital 175 by prospective, cross-sectional description. Results: There were $30.67 \%$ of patients satisfying the criteria for acute insomnia according to DSM-5. Patients with acute insomnia had a mean time of sleep-onset latency of 60 minutes, a mean total sleep duration of $4.71 \pm 1.08$ hours per night. Most patients complain of insomnia most days of the week and insomnia at the beginning of sleep accounts is common. The average number of awakenings during the night was $2.20 \pm 1.35$ times. The incidence of acute insomnia does not depend on gender, age group, or severity of traumatic brain injury. This rate is higher among patients with headache, brain contusion and/or hemorrhage, and midline displacement on CT scan of the brain.

Keyword: insomnia, traumatic brain injury

\section{I. ĐĂT VẤN ĐỀ}

Chấn thương so não (CTSN) là bệnh rất thường gặp trong thực hành lâm sàng, điều trị tốn kém, di chứng kéo dài; tạo gánh nặng về vật 
chất, tinh thần không chỉ cho bản thân người bệnh mà còn cho cả gia đình và xã hội. Đây là loại tai nạn phổ biến ở mọi quốc gia, trong đó có Việt Nam. Bên cạnh các di chứng lâu dài do chính tổn thương mô não gây ra, người bị CTSN còn có thể phát triển các bệnh lý tâm thần thứ phát. Các nghiên cứu cho thấy rối loạn về giấc ngủ mà đặc biệt là mất ngủ là chứng bệnh rất phổ biến khởi phát sớm sau CTSN. Mất ngủ có thể làm cản trở sự phục hồi chức năng và làm trầm trọng thêm các vấn đề tâm thần và di chứng thần kinh cơ. Hơn nữa, rối loạn giấc ngủ kéo dài còn là yếu tố nguy cơ hoăcc là biểu hiên sớm cho sự phát triển tiếp theo của một số bệnh tâm thần như rối loạn lưỡng cực, rối loạn trầm cảm, lạm dụng chất, ...

Chẩn đoán mất ngủ cấp tính sớm để điều trị kết hợp không chỉ có ý nghĩa quan trọng giúp phục hồi tổn thương não mà còn góp phần phòng ngừa những nguy cơ trên. Nhưng cho đến nay ở Việt Nam, vấn đề mất ngủ cấp tính sau CTSN vẫn chưa được quan tâm nghiên cứu. Vì vậy chúng tôi tiến hành đề tài: "Tỷ lệ mất ngủ cấp tính và một số yếu tố liên quan trên bệnh nhân chấn thương sọ não" nhằm mục tiêu sau:

1) Xác định tỷ lệ, đặc điểm lâm sàng mất ngủ cấp tính trên bệnh nhẩn chấn thương sọ não.

2) Đánh giá mối liên quan của một số yếu tố với mất ngủ cấp tính

\section{II. Đốl TƯợNG VÀ PHƯƠNG PHÁP NGHIÊN CỨU}

2.1. Đối tượng nghiên cứu. Nghiên cứu trên 225 bệnh nhân bị chấn thương sọ não lần đầu từ đủ 18 tuổi trở lên, khám và theo dõi điều trị tại khoa Phẫu thuật thần kinh bệnh viện Quân y 175.

2.2. Tiêu chuẩn chọn bệnh nhân vào nghiên cứu. Bệnh nhân đủ 18 tuổi trở lên bị chấn thương sọ não lần đầu do các nguyên nhân khác nhau có mất ý thức hoặc có các bằng chứng khác về bệnh lý hoặc hình ảnh trên phim chụp CT Scan sọ nã̃o đồng ý tham gia nghiên cứu.

2.3. Tiêu chuẩn loại trừ: - Bệnh nhân mắc bệnh mất ngủ, hoặc một rối loạn thức - ngủ khác hoặc có bệnh tâm thần như tâm thần phân liệt, trầm cảm, rối loạn cảm xúc lưỡng cực xảy ra trước thời điểm bị chấn thương sọ não.

- Bệnh nhân bị u não, đột quy não. Bệnh nhân lạm dụng chất ma túy, nghiện bia rượu trước khi bị CTSN, hoặc các bệnh lý nội, ngoại khoa nặng khác. Bệnh nhân có các rối loạn về trí nhớ, ngôn ngữ không thể thực hiện việc đánh giá tâm thần và làm các trắc nghiệm tại thời điểm nghiên cứu.

\subsection{Tiêu chuẩn chẩn đoán mất ngủ cấp} tính theo DSM - 5 (2013)

- Lời than phiền chủ yếu là không thỏa mãn về thời lượng và chất lượng của giấc ngủ liên quan với một hoặc hơn các triệu chứng dưới đây:

+ Khó vào giấc ngủ.

+ Khó duy trì giấc ngủ, đặc trưng bởi thức giấc nhiều lần, khó ngủ trở lại khi thức giấc.

+ Thức giấc sớm mà không thể ngủ lại được.

- Rối loạn giấc ngủ gây ra các triệu chứng khó chịu rõ rệt về lâm sàng, hoặc làm suy giảm các chức năng xã hội, nghề nghiệp hoặc các chức năng quan trọng khác.

- Khó ngủ xẩy ra ít nhất 3 tối mỗi tuần.

- Khó ngủ xâyy ra mặc dù có đầy đủ các điều kiện thuận lợi cho giấc ngủ.

- Mất ngủ kéo dài trong khoảng thời gian ít nhất một tháng.

2.5. Thiết kế nghiên cứu. Nghiên cứu tiến cứu, mô tả cắt ngang xác định tỷ lệ mất ngủ cấp tính, đặc điểm lâm sàng và một số yếu tố liên quan đến mất ngủ cấp tính phát triển trên các bệnh nhân sau CTSN từ 1-2 tháng.

\section{KẾT QUẢ NGHIÊN CỨU}

Bảng 1. Nhóm tuổi, giới tính và nghề nghiệp nguyên nhân CTSN của đôi tượng nghiên cứu

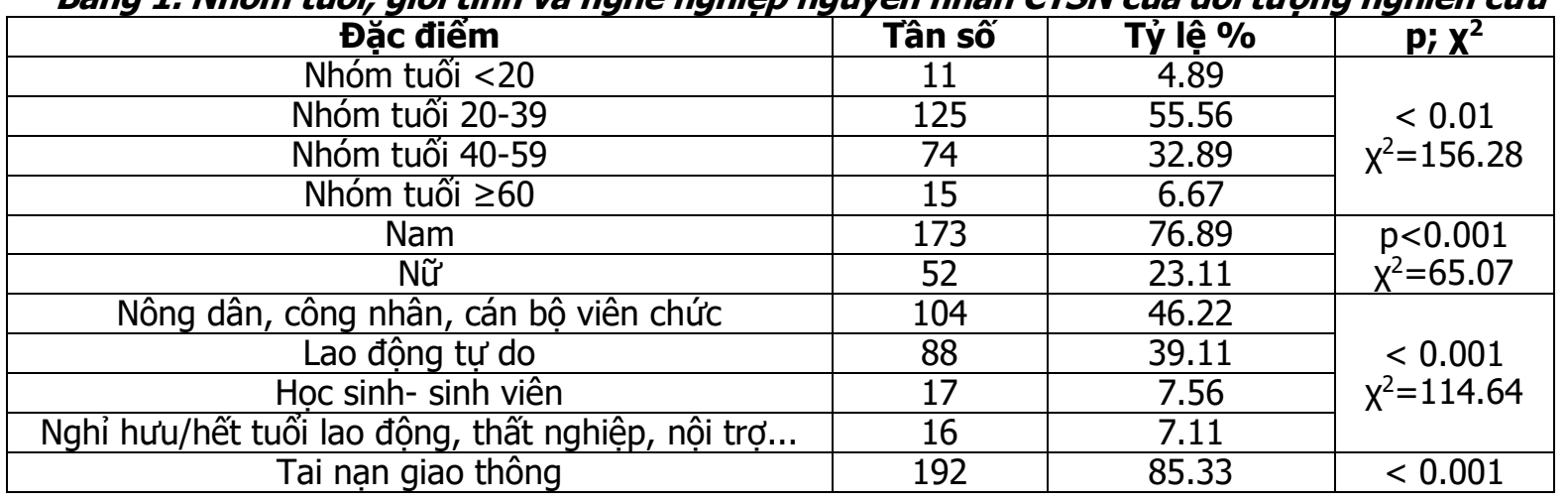


Tai nạn lao động thế thao

Bị tấn công hoặc các nguyên nhân khác

13

20

5.78

$X^{2}=274.10$

Bệnh nhân CTSN chủ yếu trong nhóm tuổi từ 20 đến 39 và từ 40 đến 59 tuối. Nhóm dưới 20 tuối và từ 60 tuổi trở lên chiếm tỷ lệ thấp hơn. Đa số bệnh nhân là nam giới. Nhóm bệnh nhân CTSN là nông dân, công nhân, cán bộ viên chức và lao động tự do chiếm tỷ lệ cao hơn các nhóm còn lại. Nhóm bệnh nhân CTSN có nguyên nhân từ Tai nạn giao thông chiếm tỷ lệ cao nhất, Sự khác biệt có ý nghĩa thống kê.

Bảng 2. Hình ảnh chụp cắt lớp vi tính sọ não lúc nhập viện của đối tượng nghiên cứu

\begin{tabular}{|c|c|c|c|}
\hline STT & Tốn thương & Tân số & Tỷ lệ \% \\
\hline 1 & Không có tốn thương não & 19 & 8.44 \\
\hline 2 & Dập và/hoặc xuất huyết não & 96 & 42.67 \\
\hline 3 & Tụ máu ngoài màng cứng & 64 & 28.44 \\
\hline 4 & Tụ máu dưới màng cứng & 89 & 39.56 \\
\hline 5 & Xuất huyết dưới nhện & 80 & 35.56 \\
\hline 6 & Di lệch đường giữa & 46 & 20.44 \\
\hline
\end{tabular}

Nhóm bênh nhân CTSN không có tốn thương não trên phim CT scan so não chiếm tỷ lệ thấp nhất (8.44\%). Nhóm bệnh nhân bị Dập và/hoặc xuất huyết não; Tụ máu ngoài màng cứng; Tụ máu dưới màng cứng; Xuất huyết dưới nhện chiếm tỷ lệ cao hơn.

3.2. Đặc điểm lâm sàng mất ngủ ở nhóm bệnh nhân nghiên cứu

Bảng 3. Các triệu chứng mất ngủ theo tiêu chuẩn DSM-5

\begin{tabular}{|c|c|c|c|}
\hline STT & Triệu chứng & Tân số/ 225 & Tỷ lệ \% \\
\hline 1 & Không thỏa mãn về thời lượng và chất lượng của giấc ngủ. & 69 & 30.67 \\
\hline 2 & Khó vào giấc ngủ & 83 & 36.89 \\
\hline 3 & $\begin{array}{l}\text { Khó duy trì giấc ngủ, đặc trưng bởi thức giấc nhiều lần, khó ngủ trở lại } \\
\text { khi thức giấc. }\end{array}$ & 61 & 27.11 \\
\hline 4 & Thức giấc sớm mà không thế ngủ lại được. & 25 & 11.11 \\
\hline 5 & Khó ngủ xấy ra mặc dù có đầy đủ các điêu kiện thuận lợi cho giấc ngủ. & 97 & 43.11 \\
\hline 6 & $\begin{array}{l}\text { Rối loạn giấc ngủ gây ra các triệu chứng khó chịu rõ rệt, hoặc làm suy giảm } \\
\text { các chức năng xã hội, nghể nghiệp hoặc các chức năng quan trọng khác. }\end{array}$ & 69 & 30.67 \\
\hline 7 & Có triệu chứng khó ngủ. & 116 & 51.56 \\
\hline
\end{tabular}

Có $51.56 \%$ tổng số bệnh nhân trong mẫu nghiên cứu báo cáo có triệu chứng khó ngủ. Khó vào giấc ngủ phổ biến hơn cả với tỷ lệ $36.89 \%$, tiếp theo là Không thỏa mãn về thời lượng và chất lượng của giấc ngủ (30.67\%). Triệu chứng khó duy trì giấc ngủ và thức giấc sớm chiếm tỷ lệ thấp hơon (tương ứng là: $27.11 \%$ và $11.11 \%$ ).

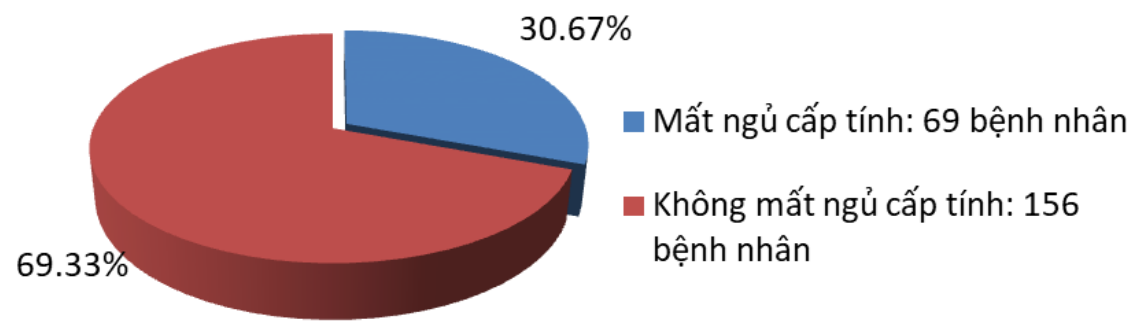

Biểu đồ 1. Tỷ lệ bệnh nhân chấn thương sọ não bị mât ngư cấp tính

Trong số các 225 bệnh nhân CTSN đáp ứng tiêu chuẩn nghiên cứu, có 69 bệnh nhân tương ứng $30.67 \%$ tổng số bệnh nhân thỏa mãn tiêu chuẩn chẩn đoán mất ngủ cấp tính.

Bảng 4. Thời gian vào giấc ngủ trung bình và thời gian ngủ được trung bình mỗi đêm

\begin{tabular}{|c|c|c|c|c|}
\hline Chỉ số nghiên cứu & Tân số & $X \pm$ SD & Min & Max \\
\hline Thời gian vào giấc ngủ trung bình (phút) & 69 & $65.65 \pm 50.34$ & 10 & 240 \\
\hline Thời gian ngù được trung bình mối đêm (giờ) & 69 & $4.71 \pm 1.08$ & 2 & 6.5 \\
\hline
\end{tabular}

Các bệnh nhân mất ngủ cấp tính có thời gian vào giấc ngủ trung bình là $65.65 \pm 50.34$ phút và số giờ ngủ được mỗi đêm trung bình là $4.71 \pm 1.08$ giờ. 


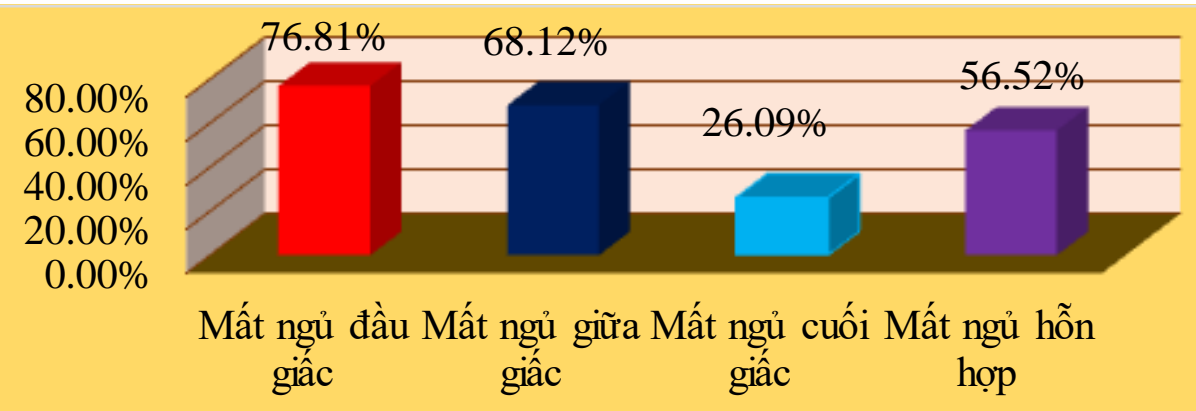

Biểu đồ 2. Biểu hiên mất ngử cấp tính của đôî tượng nghiên cứu

Biểu đồ 4: Mất ngủ đầu giấc chiếm tỷ lệ cao nhất, tiếp theo là mất ngủ giữa giấc, mất ngủ cuối giấc chiếm tỷ lệ thấp nhất. Số bệnh nhân mẩt ngủ hỗn hợp khá phổ biến.

Bảng 5. Sồ lần thức giấc trung bình trong giấc ngử đêm và mức độ mất ngủ

\begin{tabular}{|c|c|c|c|c|}
\hline \multicolumn{2}{|c|}{ Chỉ số nghiên cứu } & Tân số & Tỷ lệ \% & \multirow{3}{*}{$\begin{array}{c}\mathbf{p} ; \mathbf{X}^{\mathbf{2}} \\
<0.01 \\
\mathbf{X} 2=15.78\end{array}$} \\
\hline \multicolumn{2}{|c|}{ Thức giấc trung bình 0-1 lần/đêm } & 18 & 26.09 & \\
\hline \multicolumn{2}{|c|}{ Thức giấc trung bình từ 02 lần/đêm trở lên } & 51 & 73.91 & \\
\hline \multicolumn{2}{|c|}{ Số lần thức giấc trung bình/giấc ngủ đêm } & \multicolumn{2}{|c|}{$2.20 \pm 1.35$} & \multirow{3}{*}{$\begin{array}{c}<0.001 \\
x^{2}=22.04\end{array}$} \\
\hline \multicolumn{2}{|c|}{ Mất ngủ trung bình Ba-Năm đêm/tuần } & 15 & 21.74 & \\
\hline \multicolumn{2}{|c|}{ Mất ngủ trung bình Sáu-Bấy đêm/tuân } & 54 & 78.26 & \\
\hline \multirow{3}{*}{$\begin{array}{l}\text { Đánh giá mức độ } \\
\text { mất ngủ theo } \\
\text { thang điểm ISI }\end{array}$} & Nhẹ & 50 & 72.46 & \multirow{3}{*}{$\begin{array}{c}<0.01 \\
x^{2}=52.43\end{array}$} \\
\hline & Vừa & 17 & 26.64 & \\
\hline & Nặng & 2 & 2.90 & \\
\hline
\end{tabular}

Trong các bệnh nhân CTSN bị mất ngủ cấp tính, thức giấc trung bình từ 02 lần/đêm trở lên chiếm tỷ lệ $73.91 \%$; số lần thức giấc trung bình/giấc ngủ đêm là $2.20 \pm 1.35$ lần. Mất ngủ xuất hiện hầu hết các ngày trong tuần chiếm tỷ lệ cao nhất (78.26\%). Mất ngủ mức độ nhẹ chiếm tỷ lệ cao nhất, mất ngủ mức độ nặng chiếm tỷ lệ thấp nhất.

Bảng 6. Phân tích môi liên quan của một số yêu tố với mất ngủ cấp tính

\begin{tabular}{|c|c|c|c|c|c|c|}
\hline \multirow{2}{*}{\multicolumn{2}{|c|}{ Chỉ số nghiên cứu }} & \multicolumn{2}{|c|}{ Không mất ngủ cấp tính } & \multicolumn{2}{|c|}{ Có mất ngủ cấp tính } & \multirow{2}{*}{ p; $x^{2}$} \\
\hline & & Tân số & Tỷ lệ \% & Tân số & Tỷ lệ \% & \\
\hline \multicolumn{2}{|l|}{ Nam } & 120 & 69.36 & 53 & 30.64 & \multirow{2}{*}{$\begin{array}{c}0.99 \\
x^{2}=0.00 \\
\end{array}$} \\
\hline \multicolumn{2}{|l|}{ Nữ } & 36 & 69.23 & 16 & 30.77 & \\
\hline \multicolumn{2}{|c|}{ CTSN mức độ nhẹ } & 65 & 75.22 & 25 & 27.78 & \multirow{3}{*}{$\begin{array}{c}0.183 \\
x^{2}=3.399\end{array}$} \\
\hline \multicolumn{2}{|c|}{ CTSN mức độ vừa } & 59 & 71.84 & 22 & 27.16 & \\
\hline \multicolumn{2}{|c|}{ CTSN mức độ nặng } & 32 & 59.26 & 22 & 40.74 & \\
\hline \multirow{2}{*}{\multicolumn{2}{|c|}{$\begin{array}{l}\text { Nhóm tuôi 18-29 } \\
\text { Nhóm tuối 30-59 }\end{array}$}} & 60 & 72.29 & 23 & 27.71 & \multirow{3}{*}{$\begin{array}{c}0.608 \\
x^{2}=0.997\end{array}$} \\
\hline & & 87 & 68.50 & 40 & 31.50 & \\
\hline \multicolumn{2}{|c|}{ Nhóm tuối $\geq 60$} & 9 & 60.00 & 6 & 40.00 & \\
\hline \multirow{2}{*}{$\begin{array}{c}\text { Đau đâu sau } \\
\text { CTSN }\end{array}$} & Có & 14 & 41.18 & 20 & 58.82 & \\
\hline & Không & 142 & 74.35 & 49 & 25.65 & \\
\hline \multirow{2}{*}{$\begin{array}{l}\text { Dập và/hoắc } \\
\text { xuất huyết } \\
\text { não }\end{array}$} & Có & 59 & 61.46 & 37 & 38.54 & \multirow{2}{*}{$\begin{array}{c}x^{2}=14.93 \\
0.027 \\
x^{2}=4.88\end{array}$} \\
\hline & Không & 97 & 75.19 & 32 & 24.81 & \\
\hline \multirow{2}{*}{$\begin{array}{l}\text { Di lệch đường } \\
\text { giữa }\end{array}$} & Có & 26 & 56.52 & 20 & 43.48 & \multirow{2}{*}{$\begin{array}{c}0.035 \\
x^{2}=4.464\end{array}$} \\
\hline & Không & 130 & 72.63 & 49 & 27.37 & \\
\hline
\end{tabular}

Tỷ lệ mất ngủ cấp tính không phu thuộc vào giới tính, nhóm tuổi, mức độ chấn thương so não. Tỷ lệ này cao hơn có ý nghĩa thống kê trong số các bệnh nhân có triệu chứng đau đâu, có hình ảnh dập và hoặc/xuất huyết não, di lệch đường giữa trên phim chụp CT scan sọ não.

\section{BÀN LUÂN}

Nhóm bênh nhân tuổi từ 20 đến 39 và từ 40 đến 59 chiếm tỷ lệ khá phổ biến (55.56\%; $32.89 \%$ ) (bảng 1). Nhóm dưới 20 tuổi và từ 60 tuổi trở lên chiếm tỷ lệ thấp hơn (4.89\%; 6.67\%). Tác giả Lê Thị Yến Phụng (2016) ghi nhận kết quả tương tự: nhóm tuổi từ 19-40 chiếm tỷ lệ $60.3 \%$, nhóm tuổi 41-60 tuổi chiếm 
tỷ lệ 34.9\%; nhóm trên 60 tuổi chiếm tỷ lê 4.8\% [1]. Nhóm bệnh nhân tuổi từ 20-60 chiếm tỷ lệ cao hơn các lứa tuổi còn lại là hợp lý vì đây là lứa tuổi lao động, nên có nguy cơ bị chấn thương nói chung cao hơn. Với truyền thống của người Việt Nam, nữ giới thường làm công việc nhẹ, nội trợ; nam giới thường làm các công việc nặng nhọc; nam giới cũng thường xuyên sử dụng bia, rượu nên có nguy cơ bị CTSN cao hơn. Do vậy $76.89 \%$ số bệnh nhân nam giới trong mẫu nghiên cứu là phù hợp. CTSN có thể gặp ở các ngành nghề khác nhau, tuy nhiên do đặc thù công việc và môi trường lao động mà một số nhóm nghề nhất định có nguy cơ bị CTSN cao hơn so các ngành nghề khác. Vì vậy nhóm bệnh nhân là nông dân, công nhân, cán bộ viên chức và nhóm lao động tự do chiếm tỷ lệ cao hơn các nhóm bệnh nhân còn lại. Ở Việt Nam đa số người lao động sử dụng phương tiện tham gia giao thông bằng xe gắn máy, việc sử dụng bia rượu khi tham gia giao thông làm tăng nguy cơ bị CTSN. Kết quả cho thấy bệnh nhân CTSN do nhiều nguyên nhân khác nhau trong đó nguyên nhân từ tai nạn giao thông chiếm tỷ lệ cao nhất $(85.53 \%)$. Kết quả này phù hợp với nghiên cứu của tác giả Lê Thị Yến Phụng (2016) ghi nhận tỷ lệ này là $88.9 \%[1]$.

Tỷ lệ nhóm bệnh nhân CTSN bị Dập và/hoặc xuất huyết não khá phổ biến (42.67\%); Tụ máu ngoài màng cứng (28.44\%); Tụ máu dưới màng cứng (39.56\%); Xuất huyết dưới nhện (35.56\%) (Bảng 2). Kết quả này cũng phù hợp với tác giả Lê Thị Yến Phụng ghi nhận tỷ lệ bệnh nhân có dập não là $52.6 \%$, xuất huyết dưới nhện là $31.6 \%$, tụ máu dưới màng cứng 39.5\% [1]. Nghiên cứu của chúng tôi nhận thấy dịch chuyển đường giữa trên phim chụp $\mathrm{CT}$ scan sọ não chiếm tỷ lệ 20.44\%; phù hợp với Puffer và cs (2018) khi đánh giá mối liên quan giữa kết cục lâu dài và mức độ lệch đường giữa trên phim chụp CT sọ não ban đầu đã ghi nhận: ở nhóm bệnh nhân đánh giá sau CTSN 30 ngày với 892 bệnh nhân nghiên cứu có 697 bệnh nhân không có dịch chuyển đường giữa [8], (tỷ lệ số bệnh nhân có di lệch đường giữa tương ứng là $21.86 \%$ ). Tỷ lệ số bệnh nhân CTSN không có hình tổn thương não trên phim $\mathrm{CT}$ sọ não $(8.44 \%)$, thấp hơn nhiều so với kết quả nghiên cứu của tác giả Trương Phước Sở (2009) $(80.01 \%)$ [2]. Có thể do tác giả thực hiện nghiên cứu tại phòng khám cấp cứu, trong đó có nhiều trường hợp bệnh nhân vào khám vì chấn động não.

Có $51.56 \%$ số bệnh nhân báo cáo có triệu chứng khó ngủ, cao hơn báo cáo của Jain $\mathrm{A}$. và cs (40.2\%) [4] (Bảng 3), điều này có thể do tác giả sử dụng thang điểm ISI để phát hiện triệu chứng mất ngủ, chúng tôi đánh giá các triệu chứng mất ngủ theo tiêu chuẩn của hiệp hội tâm thần $M \tilde{y}$. Do vậy tỷ lệ này tương đồng với báo cáo của Ouellet M. C. (2006) (50.2\%) theo tiêu chuẩn DSM-IV [6]. Tuy nhiên để thỏa mãn theo tiêu chuẩn chẩn đoán mất ngủ cấp tính của DSM-5, những bệnh nhân này cần có thêm các tiêu chuẩn khác đặc biệt là rối loạn giấc ngủ phải gây ra các triệu chứng khó chịu rõ rệt, hoặc làm suy giảm các chức năng xã hội, nghề nghiệp hoăc các chức năng quan trọng khác. Kết quả ở biểu đồ 1 , tỷ lệ bệnh thỏa mãn tiêu chuẩn chẩn đoán mất ngủ cấp tính theo DSM-5 là 30.67\%, phù hợp với Ouellet M. C. và cs (2006) ghi nhận tỷ lệ này là $29.4 \%$.

Thời gian vào giấc ngủ của các bệnh nhân bị mất ngủ cấp tính trung bình là $65.65 \pm 50.34$ phút (Bảng 4). Kết quả tương đồng với Ouellet M. C. (2006) ghi nhận thời gian này là $57.88 \pm 42.56$ phút [6]. Thời gian ngủ được mỗi đêm trung bình của các bệnh nhân bị mất ngủ cấp tính là $4.71 \pm 1.08$ giờ. Số liệu này phù hợp với Duclos $\mathrm{C}$. và cs báo cáo trên một trường hợp CTSN thiếu ngủ nặng với thời gian này là $4.8 \pm 1.3$ giờ [3].

Trong số 69 bệnh nhân có mất ngủ cấp tính, tỷ lệ số bệnh nhân mất ngủ đầu giấc, giữa giấc, cuối giấc lần lượt là: $76.81 \% ; 68.12 \% ; 26.09 \%$ (Biểu đồ 2). Ouellet $\mathrm{M}$. C. và cs ghi nhận các bệnh nhân CTSN có hội chứng mất ngủ: $64.3 \%$ khó vào giấc ngủ, $76.6 \%$ khó duy trì giấc ngủ, $30 \%$ mất ngủ hốn hợp [6]. Tác giả vận dụng tiêu chuẩn DSM-IV nên mất ngủ giữa giấc và mất ngủ cuối giấc được gộp chung thành khó duy trì giấc ngủ. Như vậy các nghiên cứu đều cho thấy rối loạn mất ngủ sau CTSN có thể gặp cả mất ngủ đầu giấc, giữa giấc, cuối giấc.

Parcell D. L. (2008) trong một nghiên cứu sơ bộ có sử dụng phương pháp đa ký giấc ngủ ghi nhận rằng: bệnh nhân CTSN bị tăng giấc ngủ sóng chậm, giảm giấc ngủ REM và thường xuyên thức giấc vào ban đêm [7]. Số liệu bảng 5: Tỷ lệ bênh nhân có số lần thức giấc trung bình 2 lần/đêm trở lên cao hơn có ý nghĩa thống kê. Số lân thức giấc trung bình trong giấc ngủ đêm $2.20 \pm 1.35$ (lần). Ouellet M. C. và cs cũng ghi nhận bệnh nhân CTSN có hội chứng mất ngủ có số lần thức giấc trung bình mối đêm là $3.23 \pm 2.12$ lần [6]. Đa số bệnh nhân mất ngủ xuất hiện hầu hết các ngày trong tuần (gần $80 \%$ ). Kết quả này phù hợp với Ouellet $\mathrm{M}$. C. và CS, ghi nhận trong số các bệnh nhân CTSN có 
hội chứng mất ngủ, biểu hiện khó ngủ xuất hiện trung bình 5.7 đêm/tuần [6]. Dựa trên thang điểm ISI, mất ngủ mức độ nhẹ, vừa nặng chiếm tỷ lệ lần lượt là: $72.46 \% ; 26.64 \% ; 2.90 \%$. Tuy nhiển Jain $A$. và cs nghiên cứu 82 bệnh nhân CTSN có mất ngủ dựa trên thang điểm ISI ghi nhận các tỷ lệ này tương ứng là: $57.31 \%$; 58\%; $6.09 \%$ [4]. Như vậy các nghiên cứu đều cho thấy, rối loạn mất ngủ cấp tính sau CTSN có thể gặp với các mức độ khác nhau, mức độ nặng khá thấp.

Tỷ lẹ mất ngủ cấp tính ở nam và nữ không có sự khác biệt (Bảng 6). Jain A. và cs (2014) nghiên cứu 204 bệnh nhân CTSN bao gồm 162 bệnh nhân nam giới, 42 bệnh nhân nữ giới nhận thấy có 82 bệnh nhân mất ngủ trong đó 64 bệnh nhân là nam giới, 18 bệnh nhân nữ giới, sự khác biệt về tỷ lệ mất ngủ giữa hai giới không có ý nghĩa thống kê [4].

Có những kết quả mâu thuẫn về mối quan hệ giữa mức độ nghiêm trọng của CTSN và chứng mất ngủ. Tuy nhiên chúng tôi không thấy mối liên quan có ý nghĩa thống kê giữa tỷ lệ mất ngủ cấp tính và mức độ CTSN. Kết quả này có thể do mẩu nghiên cứu còn thấp. Nghiên cứu tỷ lệ mất ngủ trên người lớn nói chung, nhiêuu tác giả ghi nhận tỷ lệ mất ngủ có liên quan đến nhóm tuổi. Nhưng chúng tôi không thấy có sư liên quan rõ rệt giữa các nhóm tuổi với mất ngủ cấp tính. Điều này có thể do nghiên cứu của chúng tôi thực hiện trong khoảng thời gian ngắn, nên chưa nhận thây ảnh hưởng của tuổi cao với giấc ngủ. Nampiaparampil D. E. (2008) ghi nhận chứng đau đâu sau CTSN chiếm tỷ lệ là $57,8 \%$ [5]. Chúng tôi ghi nhận tỷ lệ này thấp hơn (15.56\%), có thể do chúng tôi khảo sát cắt ngang. Nhiều nghiên cứu đánh giá tác động của đau đầu sau CTSN đối với giấc ngủ, nhận thấy mất ngủ là triệu chứng phổ biến nhất. Chúng tôi cũng nhận thẩy tỷ lệ mất ngủ cấp tính cao hơn có ý nghĩa thống kê trong số các bệnh nhân có triệu chứng đau đâu. Jain A. và CS (2014) có ghi nhận tổn thương dập não gặp $40.24 \%$ trong số các bệnh nhân mất ngủ sau CTSN [4]. Số liệu bảng 6: Tỷ lệ mất ngủ cấp tính ở bệnh nhân CTSN có Dập và/hoặc xuất huyết não cao hơn tỷ lệ này ở nhóm bệnh nhân CTSN không có Dập và/hoăc xuất huyết não có ý nghĩa thống kê. Mặt khác Puffer và cs khi đánh giá mối liên quan giữa kết cục dài hạn và mức độ di lệch đường giữa trên các bệnh nhân CTSN nhận thấy rằng các bệnh nhân có mức di lệch đường giữa dưới $10 \mathrm{~mm}$ trên phim chụp CT scan sọ não lúc nhập viện cải thiện đáng kể kết quả chức năng so với những bệnh nhân có mức di lệch đường giữa trên $10 \mathrm{~mm}[8]$. Nghiên cứu của chúng tôi cũng ghi nhận rằng những bệnh nhân có lệch đường giữa có tỷ lệ mất ngủ cấp tính cao hơn so với các bệnh nhân không lệch đường giữa.

\section{KẾT LUÂ̂N}

Có $51.56 \%$ tổng số bệnh nhân trong mẫu nghiên cứu báo cáo có triệu chứng khó ngủ; $30.67 \%$ số bênh nhân thỏa mãn tiêu chuẩn chẩn đoán mất ngủ cấp tính theo DSM-5. Bệnh nhân mất ngủ cấp tính có thời gian vào giấc ngủ trung bình là $65.65 \pm 50.34$ phút, tổng thời gian ngủ trung bình mỗi đêm là $4.71 \pm 1.08$ giờ. Gần $80 \%$ số bệnh nhân than phiền mất ngủ xuất hiện hầu hết các ngày trong tuần. Mất ngủ đầu giấc chiếm tỷ lệ cao nhất, tiếp theo là mất ngủ giữa giấc, mất ngủ cuối giấc chiếm tỷ lệ thấp nhất. Số lần thức giấc trung bình trong đêm là 2.20 1.35 lần. Mất ngủ mức độ nhẹ và vừa thường gặp hơn mất ngủ mức độ nặng. Tỷ lệ mất ngủ cấp tính không phụ thuộc vào giới tính, nhóm tuổi, mức độ chấn thương sọ não. Tỷ lệ này cao hơn trong số các bệnh nhân có triệu chứng đau đầu, có hình ảnh dập và hoặc/xuất huyết não, di lệch đường giữa trên phim chụp CT scan sọ não.

\section{TÀl LIỆU THAM KHẢO}

1. Lê Thị Yến Phụng (2016), Suy giảm nhân thức sau chấn thương sọ não, Luânn Văn Thạc sĩ y học, Đai hocc Y Dược Thà̉nh phố Hồ Chí Minh.

2. Trượng Phước Sở, Tô Vĩnh Ninh, Phạm Dũng Nghiệp và cs (2009), "Nghiên cứu tình trạng chấn thương sọ não tư sau khi quy định đội mũ bảo hiểm", Y Học Tp. Hồ Chí Minh. 13(6), tr. 319- 327.

3. Duclos C., Dumont M., Potvin M. J. và cs (2016), "Evolution of severe sleep-wake cycle disturbances following traumatic brain injury: a case study in both acute and subacute phases post-injury", BMC Neurol. 16(1), tr. 186.

4. Jain A., Mittal R. S., Sharma A. và cs (2014), "Study of insomnia and associated factors in traumatic brain injury", Asian J Psychiatr. 8, tr. 99-103.

5. Nampiaparampil D. E. (2008), "Prevalence of chronic pain after traumatic brain injury: a systematic review", JAMA. 300(6), tr. 711-9.

6. Ouellet M. C., Beaulieu-Bonneau S., Morin C. M. (2006), "Insomnia in patients with traumatic brain injury: frequency, characteristics, and risk factors", J Head Trauma Rehabil. 21(3), tr. 199-212.

7. Parcell D. L., Ponsford J. L., Redman J. R. và cs (2008), "Poor sleep quality and changes in objectively recorded sleep after traumatic brain injury: a preliminary study", Arch Phys Med Rehabil. 89(5), tr. 843-50.

8. Puffer R. C., Yue J. K., Mesley M. và cs (2018), "Long-term outcome in traumatic brain injury patients with midline shift: a secondary analysis of the Phase 3 COBRIT clinical trial", J Neurosurg. 131(2), tr. 596-603. 